\title{
Turbidity measurement: its application for water resource recycling in buildings
}

\section{Article}

\section{Accepted Version}

Creative Commons: Attribution-Noncommercial-No Derivative Works 4.0

Hyde, K. (2021) Turbidity measurement: its application for water resource recycling in buildings. Process Safety and Environmental Protection, 146. pp. 629-638. ISSN 0957-5820 doi: https://doi.org/10.1016/j.psep.2020.11.019 Available at https://centaur.reading.ac.uk/95515/

It is advisable to refer to the publisher's version if you intend to cite from the work. See Guidance on citing.

To link to this article DOI: http://dx.doi.org/10.1016/j.psep.2020.11.019

Publisher: Elsevier

All outputs in CentAUR are protected by Intellectual Property Rights law, including copyright law. Copyright and IPR is retained by the creators or other copyright holders. Terms and conditions for use of this material are defined in the End User Agreement.

\section{www.reading.ac.uk/centaur}

\section{CentAUR}

Central Archive at the University of Reading

Reading's research outputs online 


\title{
Turbidity Measurement: its application for water resource recycling in buildings
}

Hyde Katherine ${ }^{1}$ School of the Built Environment, The University of Reading, Reading, Berkshire ${ }^{1}$

Dr Katherine Hyde PhD MSc FRSC CChem CSci CWEM FHEA

\section{katherine_hyde@yahoo.co.uk}

Director for Academic Tutoring and Lecturer in Environment and Sustainability Corresponding Author

\section{School of the Built Environment}

Architecture | Construction | Energy | Environmental Engineering

2 Hockeridge Wood Cottages, HP4 2SZ, UK

Tel: $+44(0) 1442879360$

This work was supported by the funding agency European Institute of Innovation and Technology, Climate-KIC, under University of Reading grant number: ARED0004_2013-1.1-009_P091_02

\author{
Abstract \\ Supplying treated greywater within buildings delivers continuous \\ additional resilience and improvements in water efficiency. This includes the \\ making available (by substitution) of greywater resources suitable for non-potable \\ purposes such as flushing toilets. Thereby, the overall daily consumption of \\ pristine potable water for flushing and other lower quality uses is reduced.
}


The empirical measurement of turbidity was confirmed as an accurate and resilient indicator of greywater quality, greywater treatment process efficiency and of well-functioning greywater reuse systems in the short-, medium- and longterm.

The methodology applies turbidity monitoring for evidential management and control of treated greywater quality, essential for greywater recycling in the building stock. The results demonstrated evidence of co-variation between turbidity and biochemical oxygen demand in a lightly-loaded greywater treatment process. Real-time monitoring of turbidity delivers responsive, reliable, in-situ and remote measurements for informing building management systems (BMS), comprising an essential part of routine monitoring of greywater treatment plant. The analytical evidence confirms the importance of turbidity measurement and control in both current and future UK and international greywater standards.

By undertaking turbidity measurements in compliance with BS 8525-2:2011, greater assurance in the use and compliance of greywater supplies in the built environment is achieved. Consequently, the rationale for including the empirical measurement of turbidity to demonstrate satisfactory management of the greywater quality, treatment system operation, monitoring and compliance in buildings has been confirmed.

Keywords:

1 Process performance and turbidity measurement;

2 Turbidity monitoring and building management systems (BMS);

3 Quality criteria in treated greywater;

4 Buildings resilience and greywater;

5 Co-variation between turbidity and biochemical oxygen demand. 


\section{1: Introduction and Background}

\subsection{Aims, objectives and the case for investigating the measurement of turbidity for}

greywater recycling.

In order to meet UN Sustainable Development Goal 6, 'Clean Water and Sanitation' (2016) for water supply and equity in availability, the production of essential volumes of water from the same traditional sources will become increasingly constrained and costly. Supplying treated greywater within buildings delivers additional climate resilience at an additional cost by increasing the amount of water available to occupants to be used for non-drinking purposes. Mains water consumption could then be expected to decrease proportionately. Following the application of a robust treatment process, the resultant greywater stream must demonstrate consistently low pollutant concentrations, 'producing a known, reliable, and acceptable water quality' (Hyde and Smith, 2020). Thus without testing, verifying and disseminating the greywater treatment efficiency and resultant treated greywater quality, progress in gaining a more widespread uptake and societal reliance upon recycling of greywater will continue to be slow. Societal reliance is influenced by public confidence and awareness. Fielding, Dolnicar and Schulz (2018) examined key research questions relating to the public acceptance of recycled water. Alharbi et al (2019) noted that the 'lack of public and social awareness' concerning 'sustainable treatment systems are some of the primary constraints for greywater recycling'. To improve public confidence and awareness, the wider publicising and implementation of robust technologies for measurement, testing and display is required. Some such systems are already available to deliver swift and accessible indications of the instantaneous quality of the treated and recycled greywater flow. The measurement of turbidity satisfies these requirements, facilitating a pathway for the wider adoption of greywater systems, when accompanied by routine testing for 
BOD and microbiology.

Regulatory frameworks are required for adoption of protocols for the safe reuse of wastewater, and for compliance with water safety, health and safety, and risk management. The latter will demonstrate the case for investment and installation to be made within a large refurbishment project for example, requiring confidence levels concerning the quality of the treated greywater that will be achieved. Improved management requirements such as for health protection, must be demonstrated (adapted from WHO, 2006).

The aim of the research was to understand and confirm the application of turbidity for making measurements of greywater treatment performance, and if suitable, to confirm potential application for future monitoring of water reuse, and to demonstrate compliance (WHO, 2006).

The objectives of the research were:

(1) to evaluate the use of turbidity measurements as a process performance indicator in the short-, medium- and long-term; also demonstrating the quantitative reliability of this parameter and its suitability for use in treatment plant control;

(2) to observe turbidity results for evaluating compliance with the British Standard BS 8525-2:2011, for which the author was the committee chair;

(3) to review the application of turbidity monitoring for broad-spectrum water recycling efficiency in performance buildings, and for future domestic applications; this includes using turbidity to enhance public understanding and awareness.

(4) to develop a better understanding of the greywater treatment process using turbidity values, whilst measuring BOD other comparator variables such as 
Electrical Conductivity (EC) in the Membrane Bio-Reactor system and in the treated greywater flows.

In the early stages, the operation of a commercial greywater system for experimental research at the University of Reading was considered for two principal reasons;

(1) to develop evidence for understanding day-to-day greywater process variance using the monitoring of turbidity and other parameters in the Membrane BioReactor system;

(2) to evaluate the long-, medium- and short-term characteristics of treatment process efficiency using turbidity and other measurements as indicators. Undertaking research using a commercial greywater system provided an experimental opportunity to evaluate processes and conditions encountered, and to study the performance of the plant under controlled conditions. The latter will demonstrate whether a case for investment and installation could be made within a large refurbishment project for example, requiring confidence levels concerning the quality of the treated greywater that could be achieved. Improved resilience will be quantifiable in future for example, by measuring the increase in the volumes of recycled greywater supplied to users and building occupants.

\subsection{Literature review}

In April 2020, the Chairman of the UK Environmental Audit Committee wrote to the Parliamentary Under-Secretary, Rebecca Pow concerning the National Audit Office report on water supply and demand management (Environmental Audit Committee). The letter outlines water supply being one of the six priority risks defined in the Climate Change Risk Assessment (Climate Change Committee, 2017) that 
includes in the highest category requiring action, risks to public water supplies from drought and low river flows, as well as risks of household water supply interruptions. Furthermore, the National Infrastructure Commission recommended increasing water capacity in England by an additional four billion litres per day to increase resilience against the growing risk of drought. In 2016, Defra published 'Creating a great place for living. Enabling resilience in the water sector' explaining that the adaptation to risks from water scarcity include the capacity for installing water reuse systems. Sapkota et al (2015) argue that centralised urban water supply systems are unlikely to meet the increasing and future water demands of urban populations so changes to the urban water service systems are required. This includes a focus on decentralized and hybrid water supply systems including wastewater reuse and rainwater harvesting. Sapkota et al (2015) also comment that further research is needed to understand and contextualise the contribution that various, complex combinations of hybrid water supply technologies will make to embedding resilience and mitigation into urban systems. They also note that collecting system-level data is critical to be able to assess the future systems performance of urban water systems and infrastructures. By extension this includes the potential contribution of greywater recycling to complex urban systems.

Greywater system reuse data has been reported by Nolde in 2000 from toilet flushing in Berlin; for non-potable urban uses (Lazarova, Hills and Birks, 2003); and with regard to the degradation of greywater organic constituents using a multistage moving bed biofilm reactor (MBBR) in 2017 (Saidi et al.). The latter system demonstrated a BOD loading rate of $2.8 \mathrm{kgBOD} / \mathrm{d}$ which approached $100 \%$ removal. In 2016, Fountoulakis et al. tested a submerged membrane bioreactor in a domestic 
property, demonstrating a percentage reduction in total suspended solids (TSS) of approximately $92 \%$, and a mean turbidity of 5.0 NTU with a turbidity removal of $97 \%$.

The technical rationale supporting the principle of water recycling was discussed in 1992, when Nolde and Dott (Nolde, 1999) explained that water from recycling systems should fulfil four main criteria; "hygienic safety"; "aesthetics"; "environmental tolerance"; and "technical and economic feasibility", notable for the authors having placed safety as the first criterion. In 2014, Behzadian et al identified three objectives for evaluating the performance of water reuse schemes; resilience, reliability and total cost. Thus, whilst the water efficiency achieved through reusing greywater is partly dependent upon the availability and installation of suitable treatment processes, the treatment must at all times be fit for purpose. It must also provide compliance with the specific uses to which the treated greywater will be put. Taylor and Stanley (1985) stated that "the quality of [water] data must be known and established before it can be used logically in any application", directly relating output quality to intended uses, as also explained by Holden (1970). Many authors have described the character and profile of greywater constituent concentrations for example; Diaper et al, (2001); Diaper, Toifl and Storey (2008); Dixon et al., (1999); Dixon, Butler, and Fewkes, (1999); Friedler, (2004); Ghaitidak and Yadav, (2013); Singh, Kaur, Ghawana and Ghaitidak, (2018); Gupta, (2018), and Wu (2019). Some authors either did not include the empirical measurement of turbidity or did not report the respective results. In "membrane-based technology in greywater reclamation: A review", Wu (2019) included a comprehensive record of analytical results including turbidity from a range of sources of greywater. However, turbidity was reported as a secondary characteristic and was not specifically discussed in terms of its own merits.

In the case of recycled greywater use within buildings, measurements of 
greywater quality and composition must be accurate and appropriate in order that they can be relied upon and that the true value of greywater can be realised. The greywater quality must be fit for purpose and suitable for its intended uses, and measurements of composition and quality are used to demonstrate and verify this. Secondly, the greywater must be legally compliant and measurements of composition and quality are needed in order to demonstrate that using the treated greywater will not cause human or personal harm for example to health, nor generate nuisance, nor distribute any pollutants. Thirdly, it is possible for treated greywater to comply with both the first and second criteria and yet nevertheless to be unpleasant due to aesthetic attributes such as colour, meaning that colour criteria should be included in certain circumstances.

\subsection{Development and application of greywater standards}

Standards for achieving greywater quality control in buildings were formulated by the British Standards Institution as BS 8525-1:2010 and 8525-2:2011 through research and dialogue with industry, government scientists and academics. Part 1 comprises a Code of Practice and Part 2 provides the specific test arrangements for greywater treatment plant. Five quantitative quality standards were specified for constituents, including turbidity.

The BS8525 approval process first assesses the performance of a greywater treatment plant during installation and commissioning. The commissioning confers confidence of the quality requirements for treated greywater supplies being achieved in water supplied from that treatment plant, that could potentially be situated in remote locations. 
The international BS ISO 20761 "Water reuse in urban areas - Guidelines for water reuse safety evaluation - Assessment parameters and methods" (2018) includes non-quantitative principles for safety evaluation, water quality and turbidity measurement. A "fit-for-purpose water reuse safety evaluation" should be carried out according to the "intended uses". The scope of the standard also allows the inclusion of highly polluted sources. In contrast, BS8525-2:2011 excludes the use of highly polluted raw water sources for recycling, including wastewater from cooking, kitchens and dishwashing machines. By setting standards for lightly polluted greywaters it was possible to take a more precise view of the types of specifications for treatment units.

The BS8525-2:2011 standard for domestic greywater is providing industry and the public with confidence in the selection and use of the most critical greywater system tests that can be supplemented, adding further detailed tests where required. The list of acceptable maximum constituent concentrations is specified according to the intended uses of the greywater, for example, whether for spray applications or non-spray applications.

The whole life review of the fate and recycling of low concentrations of contaminants originating from the influent greywater provides an interesting context in comparison with more highly organically contaminated recycling systems. More contaminated or highly loaded effluent flows offer a good potential for biological digestion and nutrient by-products. Lighter organic influent loads mean that lower volumes of filtrate waste arise as a by-product of the oxidation and nanofiltration stages. In these cases, the energy consumption and emissions footprint requires a respectively less intensive treatment infrastructure. The carbon commitment required to achieve the benefit of a recycled resource stream used primarily for flushing toilets, delivers the resilience of an in-house resource provision. Furthermore, because the influent 
greywater is lightly loaded, the treated greywater quality is produced efficiently. No exceptions have been observed in the quality of the greywater delivered for reuse.

The permitted physico-chemical and biochemical concentrations in treated greywaters compliant to BS 8525-2:2011 are shown in Table 1, (2011).

\begin{tabular}{|c|c|c|c|c|c|}
\hline \multirow[t]{2}{*}{ Parameter } & \multirow{2}{*}{$\begin{array}{l}\quad \begin{array}{c}\text { Spray } \\
\text { applications }\end{array} \\
\text { Pressure } \\
\text { washing, garden } \\
\text { sprinkler use } \\
\text { and car washing }\end{array}$} & \multicolumn{3}{|c|}{ Non-spray applications } & \multirow{2}{*}{$\begin{array}{c}\text { Included } \\
\text { analytical test } \\
\text { method }\end{array}$} \\
\hline & & WC flushing & $\begin{array}{l}\text { Garden } \\
\text { watering }\end{array}$ & $\begin{array}{l}\text { Washin } \\
\mathrm{g} \\
\text { machin } \\
\text { e use }\end{array}$ & \\
\hline $\begin{array}{l}\text { Turbidity } \\
\text { NTU }\end{array}$ & $<10$ & $<10$ & N/A & $<10$ & $\begin{array}{l}\text { BS EN ISO } \\
7027\end{array}$ \\
\hline $\mathrm{pH}$ & $5-9.5$ & $5-9.5$ & $5-9.5$ & $5-9.5$ & BS 1427 \\
\hline $\begin{array}{l}\text { Residual chlorine * } \\
\mathrm{mg} / \mathrm{L}\end{array}$ & $<2.0$ & $<2.0$ & $<0.5$ & $<2.0$ & $\begin{array}{l}\text { BS EN ISO } \\
7393-2\end{array}$ \\
\hline $\begin{array}{l}\text { Residual bromine * } \\
\mathrm{mg} / \mathrm{L}\end{array}$ & 0.0 & $<5.0$ & 0.0 & $<5.0$ & $\begin{array}{l}\text { Blue Book } \\
218, \text { Method } \\
\text { E10 [N1] }\end{array}$ \\
\hline
\end{tabular}

Table 1: Standard chemical and physical quality requirements for treated greywater for type tests, (BSi, 2011).

(C) British Standards Institution (BSI - www.bsigroup.com). Extract reproduced with permission. Source: BS 8525-2:2011.

The significance of routinely applying turbidity measurement for the effective management and control of greywater systems was discussed in relation to the British Standard, published as BS 8525-1:2010 (2010) and BS 8525-2:2011 (2011). DaviesColley and Smith (2007) argued that "turbidity is only a relative measure of (light) scattering that has no intrinsic environmental relevance until calibrated to a 'proper' scientific quantity". Their research analysed aesthetics, contact recreation, and fish habitat, using a visual clarity determination as measured by Secchi or black disc. Such a measurement technique cannot be used in buildings. In the context of building water quality, nephelometric turbidity measurements are made using more advanced 
spectrophotometric instrumentation. Nine international turbidity standards and guidelines measured using this approach are shown in Table 2.

Table 2: International greywater reuse standards and guideline concentrations, (from Smith M.J., 2017).

\begin{tabular}{|c|c|c|c|c|c|c|c|c|}
\hline $\begin{array}{l}\text { Country } \\
\text { (ref) }\end{array}$ & $\begin{array}{l}\text { Reuse } \\
\text { applications }\end{array}$ & $\mathrm{pH}$ & $\begin{array}{l}\text { TDS } \\
\text { (mg/ } \\
\text { l) }\end{array}$ & $\begin{array}{l}\text { Turb- } \\
\text { idity } \\
\text { (NTU) }\end{array}$ & $\begin{array}{l}\text { BOD }_{5} \\
(\mathrm{mg} / \mathrm{l})\end{array}$ & $\begin{array}{l}\text { Total } \\
\text { colif- } \\
\text { orms }\end{array}$ & $\begin{array}{l}\text { Faec- } \\
\text { al } \\
\text { colif- } \\
\text { orms }\end{array}$ & Extra \\
\hline $\begin{array}{l}\text { Australia } \\
\text { (Australian } \\
\text { capital } \\
\text { Territory, } \\
2007 \text { ) }\end{array}$ & $\begin{array}{l}\text { Irrigation; } \\
\text { Toilet } \\
\text { flushing; } \\
\text { laundry; car } \\
\text { washing }\end{array}$ & - & - & - & $<20$ & - & - & $\begin{array}{l}\text { Thermotolerant } \\
\text { coliforms } \\
<10 / 100 \mathrm{ml} \\
\text { Electrical } \\
\text { conductivity } \\
450-550(\mu \mathrm{s} / \mathrm{cm})\end{array}$ \\
\hline $\begin{array}{l}\text { Canada } \\
\text { (Canadian } \\
\text { Guidelines, } \\
\text { 2007) }\end{array}$ & $\begin{array}{l}\text { Toilet } \\
\text { flushing }\end{array}$ & - & - & $\leq 2$ & $\leq 10$ & - & - & $\begin{array}{l}\text { Thermotolerant } \\
\text { coliforms and } E \text { - } \\
\text { coli } \leq 200 / 100 \mathrm{ml} \\
\max \end{array}$ \\
\hline
\end{tabular}

\begin{tabular}{|c|c|c|c|c|c|c|c|c|}
\hline $\begin{array}{l}\text { Germany } \\
\text { Nolde, } \\
\text { (1999) }\end{array}$ & $\begin{array}{l}\text { Toilet } \\
\text { flushing }\end{array}$ & - & - & ND & $\begin{array}{l}5 \\
\left(\mathrm{BOD}^{7}\right)\end{array}$ & $\begin{array}{l}<100 / m \\
\text { । }\end{array}$ & $\begin{array}{l}<10 / \mathrm{m} \\
\text { । }\end{array}$ & $\begin{array}{l}\text { Pseudomonas } \\
\text { aeruginosa } \\
<1 / \mathrm{mL}\end{array}$ \\
\hline $\begin{array}{l}\text { Israel Oron } \\
\text { et al, 2014) }\end{array}$ & $\begin{array}{l}\text { Toilet } \\
\text { flushing and } \\
\text { irrigation }\end{array}$ & - & - & $\leq 10$ & $<20$ & - & $\begin{array}{l}\leq 100 / \\
100 \mathrm{ml}\end{array}$ & - \\
\hline $\begin{array}{l}\text { Italy } \\
\text { (Chaillou et } \\
\text { al, 2010) }\end{array}$ & $\begin{array}{l}\text { Irrigation; } \\
\text { urban reuse }\end{array}$ & $\begin{array}{l}\text { 6- } \\
9.5\end{array}$ & - & - & $<20$ & - & - & $\begin{array}{l}\text { COD } \leq 10 \mathrm{mg} / \mathrm{l}, \\
\text { E-coli }<10 / 100 \mathrm{ml} \\
\text { Salmonella:ND }\end{array}$ \\
\hline $\begin{array}{l}\text { Spain } \\
\text { (Chaillou et } \\
\text { al, 2010) }\end{array}$ & $\begin{array}{l}\text { Urban } \\
\text { residential } \\
\text { reuse }\end{array}$ & - & - & $\leq 2$ & - & - & - & $\begin{array}{l}\text { E-coli }<0 \\
\text { Nematode } \\
1 \text { egg/10l }\end{array}$ \\
\hline USA & $\begin{array}{l}\text { Unrestricted } \\
\text { use, Toilet }\end{array}$ & $6-9$ & - & $<2$ & $\leq 10$ & - & $\begin{array}{l}\mathrm{ND} / 10 \\
\mathrm{Oml}\end{array}$ & - \\
\hline
\end{tabular}




\begin{tabular}{|c|c|c|c|c|c|c|c|c|}
\hline $\begin{array}{l}\text { (EPA, } \\
2012)\end{array}$ & $\begin{array}{l}\text { flushing, } \\
\text { irrigation, car } \\
\text { washing and } \\
\text { agricultural } \\
\text { irrigation }\end{array}$ & & & & & & & \\
\hline $\begin{array}{l}\text { USA } \\
\text { (EPA, } \\
2012)\end{array}$ & $\begin{array}{l}\text { Restricted, } \\
\text { Public areas, } \\
\text { golf courses, } \\
\text { green belt, } \\
\text { residential, } \\
\text { cemeteries }\end{array}$ & $6-9$ & - & - & $\leq 30$ & - & $\begin{array}{l}<200 / \\
100 \mathrm{ml}\end{array}$ & - \\
\hline $\begin{array}{l}\text { China } \\
\text { (Ernst et al, } \\
2006 \text { ) }\end{array}$ & $\begin{array}{l}\text { Toilet } \\
\text { flushing }\end{array}$ & $6-9$ & $\begin{array}{l}<15 \\
00\end{array}$ & $<5$ & $<10$ & - & $\begin{array}{l}<3 / 10 \\
0 \mathrm{ml}\end{array}$ & - \\
\hline $\begin{array}{l}\text { China } \\
\text { (Ernst et al, } \\
2006)\end{array}$ & Irrigation & $6-9$ & $\begin{array}{l}<10 \\
00\end{array}$ & $<20$ & $<20$ & - & $\begin{array}{l}<3 / 10 \\
0 \mathrm{ml}\end{array}$ & - \\
\hline $\begin{array}{l}\text { China } \\
\text { (Ernst et al, } \\
2006)\end{array}$ & Washing & $6-9$ & $\begin{array}{l}<10 \\
00\end{array}$ & $<5$ & $<6$ & - & $\begin{array}{l}<3 / 10 \\
0 \mathrm{ml}\end{array}$ & - \\
\hline $\begin{array}{l}\text { UK } \\
\text { (BSI, 2011) }\end{array}$ & $\begin{array}{l}\text { Toilet } \\
\text { flushing, } \\
\text { Garden } \\
\text { irrigation, } \\
\text { Washing } \\
\text { machines }\end{array}$ & $\begin{array}{l}5- \\
9.5\end{array}$ & - & $<10$ & - & $\begin{array}{l}\leq 1000 / \\
100 \mathrm{ml}\end{array}$ & - & $\begin{array}{l}\text { Bromine }<5 \mathrm{mg} / \mathrm{l} \text {, } \\
\text { E-coli - } \\
25 / 100 \mathrm{ml} \text { - toilet } \\
\text { flushing and } \\
\text { garden } \\
\text { watering. E-coli- } \\
10 / 100 \mathrm{ml} \text { for } \\
\text { same } \\
\text { applications }\end{array}$ \\
\hline
\end{tabular}

Table 2 shows a range of international water quality standard and guideline concentrations (usually maxima), that require measurement to determine whether the greywater complies with the relevant laws and standards. The significance of each test selected relates to the quality compliance required by the authorising government or standards agency. There are nine turbidity standards that set turbidity limits ranging between $<20$ NTU for irrigation in China (Ernst et $a l$, 2006), to $\leq$ 2NTU for toilet flushing in Canada, to $\leq$ 2NTU for urban residential reuse in Spain (Chaillou et $a$, 2010) and to $\leq 2 \mathrm{NTU}$ for 'unrestricted use, toilet flushing, irrigation, car washing and agricultural irrigation' in the USA (USEPA, 2012). Whilst this is a tighter restriction 
than BS8525:2-2011 with respect to toilet flushing, it is less constrained regarding spray irrigation.

The standard BS 8525-2:2011 prescribes various chemical and microbiological methods that were used as the basis for analysing and sharing the results. The limits for E.coli at 25 per $100 \mathrm{ml}$ and Intestinal enterococci at 10 per $100 \mathrm{ml}$ were agreed by the BS Committee. The specific definition for the bacterial limits was standardised with reference to other common UK standard limits. However, a stipulation was added that E.coli and Intestinal enterococci must not be present in greater numbers after a storage time of 20 days under test conditions. E.coli and Intestinal enterococci must be absent if the treated greywater is to be used in washing machines.

A consistent $\mathrm{pH}$ range in treated greywaters must be maintained to ensure the greywater has relatively stable constituent molar balances of carbonate, bicarbonate, and carbonic acid. This resists potential toxicity and process changes from incoming untreated greywater, for example, due to metal ions. Either residual chlorine or residual bromine standards are applied when final disinfection of the treated greywater is required, for example for flushing toilets in public buildings. Very low concentrations of E. coli and Intestinal enterococci are allowed for this application, but must be absent (that is, $<1$ per $100 \mathrm{ml}$ ) for use in any spray applications such as irrigation involving treated greywater.

International water quality standards maintain and raise societal awareness of these critical requirements for water quality control. Societal values cannot be acted upon without the design, engineering, manufacture, installation and maintenance of systems for satisfying those values. Measurement of quality and composition must be accurate so that greywater quality increasingly gains public confidence in its safe use and application. 
Technical characteristics and sociological responses to greywater are closely interrelated since humans seek reliance upon technical systems whilst living and working within buildings. The quality and the public perception of greywater both independently and inter-dependently firstly, impose rigorous requirements in the delivery, operation and acceptance of satisfactory greywater systems in the built environment; secondly, they support the "debate about sociotechnical futures being embedded in emerging technologies" (Konrad and Bohle, 2019); and thirdly, they substantiate the verifiable quality of the treated greywater through published reporting and declarations of the constituent concentrations.

When failures have occurred in achieving greywater standards, the failure events are instrumental in motivating mitigation and promoting changes in practices and installations (Millard, 2017). In cases where there is clear evidence of poor performance of greywater systems, the UK Water Regulations Advisory Scheme (WRAS, 1999) may be called upon to advise, instruct and impose remedial action. Standards are also applied for evaluating treatment processes and regimes, and for making regular improvements. In this context, the research undertaken has confirmed the contribution made by the measurement of turbidity, as well as other parameters, for regulatory specification.

As a result of our analytical research, the inclusion of turbidity monitoring and control is recommended for all future greywater standards, both internationally and in the UK.

\subsection{Risk minimisation and avoidance}

Casey et al (2020) describe how 'current water infrastructure designs and design processes are ill-suited' for responding to the very considerable uncertainties imposed by climate variability and change. Whilst a more resilient approach will provide adaptability and longevity, the engineering designs and models are currently based on 
'hydrologic stationarity and well-characterised uncertainty' and a lack of reliable estimates for critical variables, (Casey et al, 2020). They describe an optimising methodology for application in circumstances of deep uncertainty, addressing potential performance and resilience across a greater range of future scenarios.

The body of evidence relating to greywater treatment systems increasingly demonstrates greater opportunities for greywater utilisation, as well as providing more acuity in assessing and avoiding risks. Risk reduction and avoidance using clear design, and careful renovation and maintenance procedures include; (1) risks to users of mains water arising from potential cross-contamination of mains systems through misconnection or other errors; (2) risks to users of greywater from contamination that could arise from the greywater itself, which might occur if the greywater were not treated appropriately prior to use; (3) other risks to users of greywater described in the literature, for example avoidance of pathogenic aerosols. These risks present a challenge to greywater manufacturers, installers and users, to monitor and make regular checks and tests of greywater quality, from installation, through daily and weekly operation and final de-commissioning. This can be achieved by the regular addition of turbidity as a monitoring parameter.

\section{2: Methods and Laboratory Tests}

\subsection{Background}

A paucity of evidence and data in the literature was observed regarding performance of greywater systems in-situ, during day-to-day operation. Wu (2019) has recently reported a 'lack of long-term membrane operation data'. Our Membrane BioReactor (MBR) research contributes towards international evidence about greywater treatment. A suite of tests was applied to evaluate treatment efficiency using a commercially available MBR unit and nanofiltration 
process with a treatment capacity of 1,100 litres per day. The application of turbidity measurement, for monitoring treatment performance and for process control was assessed.

An aerated membrane bioreactor (MBR) was installed in the Engineering Laboratories at the School of the Built Environment during summer 2013 using primarily, a German plant design and configuration (Aquality, 2015). This design (see Figure 1) was chosen in order to study treatment performance and its measurement under close-to-true operating conditions. The treatment plant applies aeration and nanofiltration to lightly organically-loaded domestic greywater. The system includes a nanofiltration membrane with a pore size of $38 \mathrm{~nm}$ which retains bacteria in the reaction tank $(\operatorname{tank} 1)$.

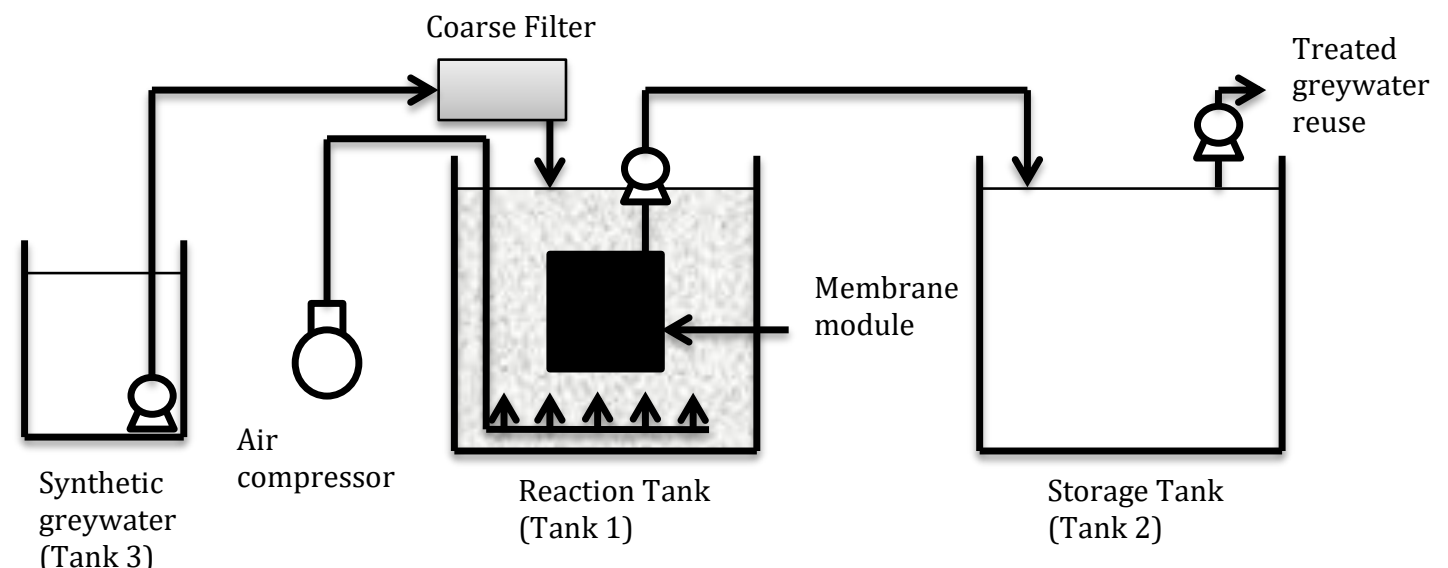

Figure 1: Process schematic of the treatment plant used in the experimental work

The standard BS 8525-2:2011 requires water quality measurements to be recorded as limiting and controlling factors during the operation of greywater systems. The measurements were made using (1) quantitative bench (laboratory) techniques and methods; as well as by (2), instantaneous measures of the spectrophotometric methods. 


\subsection{Operational and experimental setup}

The composition (recipe) for making up the synthetic type-testing greywater, given in BS 8525-2:2011, was slightly modified for the research programme as shown in Table 3 since the proportion of shower gel had to be reduced to avoid excessive foaming in tank 1 caused by the aerating pump. The BS 8525-2:2011 Committee identified a relatively short list of constituent criteria, reflective of previously referenced synthetic greywater chemistry (see for example Diaper, Toifl and Storey, 2008).

\begin{tabular}{|l|c|}
\hline Components & Volume (ml) \\
\hline Mains Water & 98,300 \\
\hline Final effluent (settled sewage effluent) & 1,630 \\
\hline Shower gel (body gel detergent) & 8.6 \\
\hline Sunflower Oil & 1.0 \\
\hline$\underline{\text { All }}$ & $\begin{array}{c}100,000 \mathrm{ml}(100 \\
\text { litres })\end{array}$ \\
\hline
\end{tabular}

Table 3: Modified composition (recipe) for synthetic type-testing of greywater in the MBR, (based on BSi, 2011).

The hydraulic loading rate was 1,100 litres per week, comprising 220litres of synthetic greywater at five times per week, giving a daily average of 157(.1429) litres per day at a 6-month average concentration of $4.86 \mathrm{mg} / \mathrm{l}$ BOD between 8 Jan 2015 and 7 May 2015. This produces an average daily organic loading rate of $763.7 \mathrm{mg} . \mathrm{d}^{-1} \mathrm{BOD}$, $\left(0.76 \mathrm{~kg} . \mathrm{d}^{-1}\right)$. The Hydraulic Retention Time (HRT) varied between 72 and 120 hours.

The database of analytical results recorded synthetic greywater influent quality, reactor tank results and treated greywater quality during a long-term programme from January 2014 to 22 February 2016, as well as during the stabilisation phase occurring during autumn 2013. Unit plant performance was measured by the change in concentrations between influent and treated greywater outflow. This established whether the treated outflow will be of a sufficient quality to meet the British Standard. 
By applying the BS 8525-2:2011 performance testing on both an operational and experimental basis, a robust approach to the scientific method was established.

Once treated greywater had passed through the membrane it was transferred to the treated greywater storage tank (tank 2) for short-term storage. The membrane was changed on 12 May 2015 and subsequently, a short period was observed during which the membrane performance re-stabilised.

\section{3: Greywater measurements and in situ procedures}

The constituent concentrations studied at the Engineering Laboratories were measured using conventional water analysis, including potentiometric techniques, light scattering measurement for turbidity, spectrophotometry and flame photometry, autoanalysis and oxygen depletion measurement by BOD. The application of small variations in feedstock, allowed chemical and biochemical processes to be evaluated. The synthetic greywater influent and treated greywater quality determinands were recorded in the database of analytical results.

In general, the principal approaches to measuring and monitoring water quality were applied using two categories;

(1) instantaneous measurements, often potentiometric and made in mid-stream, within the pipe, or in a process vessel or tank;

(2) laboratory analysis using wet-chemistry, advanced analytical chemistry, and spectrophotometric measurement.

The greywater experimental research measured turbidity using a Hach 1720E relying upon a Diffuse Transmission Spectroscopy techniques at 860nm. The measurement standard quoted by the manufacturers was Turbidity according to EN ISO 7027 "The measurement of the attenuation of a radiant flux". 
The turbidity test relies on the principle of a beam of light being scattered by suspended and colloidal particles in a water sample. British Standard 8525-2:2011 requires the turbidity measurement of the treated greywater to be less than 10 NTU, which can be compared with the UK Government's standard for drinking water of a maximum 4 NTU. The 10 NTU standard was debated and selected by the scientific committee based on a number of factors including, the importance of water clarity as a quality parameter for public and private greywater supplies; also, the chemistry and microbiology of colloidal materials and substrates.

\subsection{Results}

The results addressed the four research objectives. They showed that greywater quality and quality criteria play an essential role in meeting future resilience requirements of the building stock through regulating the quality of greywater recycling and reducing the volumes of pristine water used for nonpristine requirements. During monitoring of the treated greywater, the turbidity measurements and microbiological check results were in agreement concerning the quality status of the greywater, which met the BS 8525-2:2011 standard on all occasions, satisfying the second research objective.

By routinely applying test methodologies for turbidity and $\mathrm{pH}$, particularly when combined with the results of BOD and microbiological tests from a commercially available plant, the results provide research data upon which treated greywater operations and compliance can be examined for buildings. These data confirmed turbidity measurement to be an accurate indicator of greywater quality and greywater treatment efficiency, see Figures 2 and 3. A co-variation between turbidity and biochemical oxygen demand was also observed. This suggests that, whilst the BOD test requires at least 5 days for full evaluation, which normally 
limits its application to non-emergency monitoring, an operational relationship between turbidity and BOD results for a particular treatment plant, established by continuous turbidity monitoring, may prove useful in an emergency. This would alert the plant manager to organise immediate supplementary sampling and testing for BOD.

The competency of the treatment unit was demonstrated by applying the British Standard greywater composition (or 'recipe') for the raw bathroom greywater (synthetic) supply feed into the treatment plant. Instantaneous samples taken before and after treatment were analysed and thus, the relative treatment effectiveness was determined, see Figures 2 and 3. The treatment including nano-filtration when applied to the lightly loaded greywater, achieved a good reduction of $90 \%$ of the concentration in suspended matter, as well as reductions in total solids, colour, and turbidity.

The experimental design was reviewed at the end of phase 1 . The organic loading had been maintained at a low level in the first phase to reflect the behaviour of a treatment plant receiving influent largely from handbasins only. This would be typical of many office blocks. An early design intention had been to increase the loadings once the performance at low loading was sufficiently stable over a period of time. The design review included discussion with the German plant designers. The organic loading was increased to test the performance characteristics of the plant during the second phase of experimentation. The treatment system in tank 1 exhibited an improving reduction in turbidity during phase 2 . 


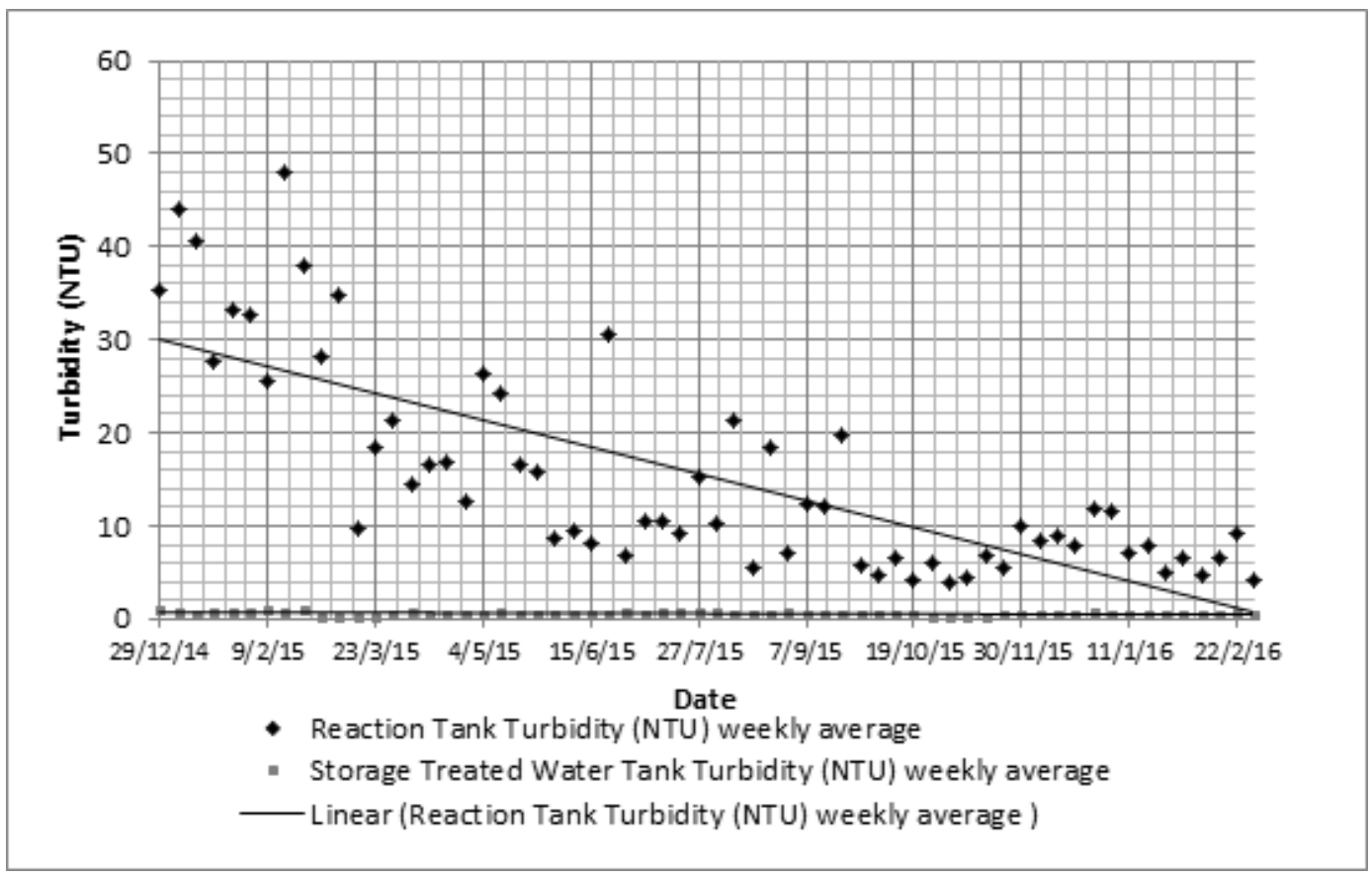

Figure 2: Process stabilisation measured in Nephelometric Turbidity Units (NTU)

following the $100 \%$ increase in organic loading to the reaction tank (Tank 1) in

November 2014 (from Smith M.J., 2017).

The analytical evidence in Figure 2 shows the well-established, consistent relationship between the required reduction in turbidity, the improvement in system efficiency and increasing stability in the greywater treatment process. This confirms the importance of including turbidity measurement in UK and international greywater standards. It also underlines the decision by the British Standards Committee for BS 8525-2:2011 to establish turbidity as an important physico-chemical parameter for future uniform inclusion in greywater testing. This confers reliance upon turbidity for confirming greywater quality using a simple test procedure that can be performed routinely and with operational confidence. 


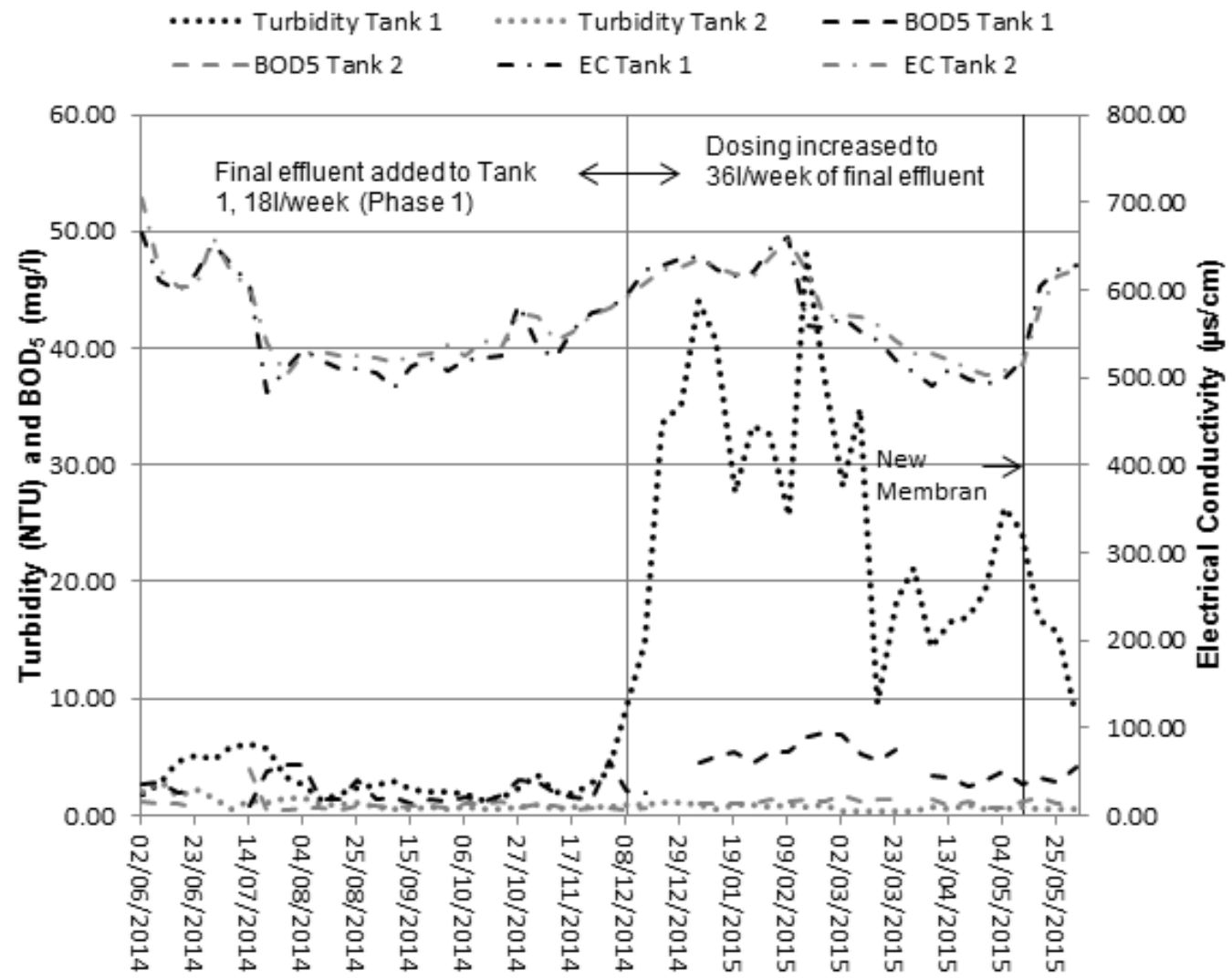

Figure 3: Twelve-month longitudinal study of treatment performance measured by turbidity (NTU), BOD $5(\mathrm{mg} / \mathrm{l})$ and electrical conductivity $(\mu \mathrm{S} / \mathrm{cm})$ showing two influent phases, (from Smith M.J., 2017).

The real-time monitoring of turbidity delivered responsive, reliable measurements that can inform building management systems (BMS) and that will support the remote scrutiny of routine greywater treatment functions. Figure 3 shows the results that satisfy objective 4, developing the understanding of the greywater treatment process using turbidity monitoring, whilst applying BOD and Electrical Conductivity (EC) as comparator variables in the Membrane Bio-Reactor system. It can be seen in Figure 3 that the turbidity of the treated greywater in Tank 2 throughout both test phases, was less than 1 NTU from the start of the testing programme in January 2014. In contrast in phase 1 , the corresponding influent turbidity was determined to have a mean of approximately 6 NTU at the start of the experimental period. That 
concentration increased significantly to between 40-50 NTU in phase 2 when the proportion of final sewage works effluent (FE) was doubled within the equivalent volume of synthetic greywater. Subsequently, the turbidity readings decreased as the process was biochemically stabilising.

Although the electrical conductivity $(\mathrm{EC})$ readings demonstrated small maxima during the experimental period, the amount of variation in average EC values showed little correspondence with changes in turbidity. This lack of a functional relationship to any degree of co-variation between EC and influent turbidity, or between EC and other parameters, demonstrates that EC will not be a suitable choice of parameter for process control. During the same corresponding phases, the measurements of influent BOD were low prior to the doubling in the proportion of FE in the recipe feed, resulting in the BOD concentration in the mixed feed being approximately doubled. Subsequently, consistency in the readings of BOD concentration in the treated greywater then remained higher after process stabilisation than prior to the doubling of the volume of FE.

Although the increase in BOD concentrations was a good indicator of increases in organic strength of the greywater, the turbidity measurements proved to be a covariant that was more sensitive to changes in influent quality. This fact confirmed the proposition that turbidity measurements are suitable for daily monitoring applications. Dependent on the type of process and the greywater use in a building, undertaking the 5-day BOD test two to three times per week is likely to deliver useful operational information if supplemented by turbidity results.

The results demonstrated the consistency of performance of the turbidity measurement; firstly, in the precision of the measurement as recorded in the laboratory, and secondly in the variance of the turbidity readings of the treated greywater. The latter 
variance was $0.05 \mathrm{NTU}$ compared to the variance of the influent at mixing which was 22.4 NTU. So, for 631 degrees of freedom in total, at a 95\% confidence level, the null hypothesis is strongly rejected at a P-value of 4.07E-67. Therefore, the observed relationship between the untreated and treated greywater is confirmed.

Based on the results of the longitudinal data, the turbidity removal efficiency of the overall process achieved almost $100 \%$ for 15 months, and the BOD treatment efficiency achieved $70 \%$ removal over the same period. Whilst achieving a low concentration of turbidity following the primary and secondary treatment stages, the addition of chlorination or bromination may be required for final disinfection. The low levels of residual organic content and turbidity following nanofiltration exert only small oxidation demand from the disinfection process. The residual chlorine in the treated water system retains its disinfecting properties and assists in maintaining good quality in the recycled water during reuse.

In calculating the pollutant load discharged by the treatment plant to the environment, the most conservative soluble ions, principally sodium, are present in the treated filtrate at concentrations that are little affected by the treatment process. The starting influent comprises lightly loaded greywater and the sodium concentrations are in the range 12.61-29.17 mg/l; average $18.74 \mathrm{mg} / \mathrm{l}$. The treated filtrate sodium concentrations are in the range $10.20-26.75 \mathrm{mg} / \mathrm{l}$; average $17.57 \mathrm{mg} / \mathrm{l}$. The largest component by volume of lightly-loaded greywater consists of mains water, which thereby contributes the majority of the total sodium load. The sodium concentrations in greywater deviated minimally from the sodium concentrations in the mains water. Sodium results showed between minimal to no soil accumulation of sodium from watering with treated greywater in comparison with watering with mains water during six months of irrigation. Statistical review did not confirm any evidence of marginal 
accretion in soil. Thereby, using greywater filtrate for propagation of plants for urban green-blue infrastructure, and by disposing of the planting media once per year, the sodium burden to the environment statistically shows no difference from irrigation using mains water. Therefore, the conservation of mass using sodium as the indicator, shows no additional burden to the environment from the recycling and use of treated greywater. Analysis of mineral accretion on the nanomembranes showed the composition to be predominantly composed of calcium species. The end-of-life planting media is disposed of annually through accredited hazardous waste procedures.

The environmental burden to sewer through disposal of filter wash-water is not detectable since the operating programme for tank one, including the hourly aeration cycle, is designed to maintain a stable microbiological community on the nano-filter array. The sodium balance assessed by combining the output aqueous phase, the soil content and plant leaf material led to inconclusive variations in results, though there was some evidence of minor accumulation in plant leaf material. Using evidence of the conservation of sodium mass in the aqueous phase and due to the high solubility of sodium, it is assumed that the majority of the environmental load of sodium and thereby other conservative and biodegradable constituents, is delivered to the soil and to planting.

\section{Discussion}

By demonstrating that greywater turbidity results can be appropriately applied for the continuous monitoring of operational process control in greywater treatment systems, the objectives were met in the following ways;

(1) the practical application of turbidity measurement performed well as a process performance indicator in the short-, medium- and long-term; it also 
demonstrated the quantitative reliability of turbidity for use in treatment plant monitoring and control;

(2) the turbidity results measured and reported were able to demonstrate continuous and practical compliance with the British Standard, BS 8525-2:2011;

(3) it is therefore suggested that wider practical application of turbidity monitoring for broad-spectrum water recycling efficiency in buildings should be routinely incorporated into both the systems themselves, and into telemetry displays for occupant awareness;

(4) a better theoretical and practical understanding was developed of the greywater treatment process using turbidity values, whilst comparing BOD and Electrical Conductivity (EC) as comparator variables in the influent and treated effluent flows;

In this way it is proposed that incorporating practical turbidity measurement and visual displays can begin to more widely enhance public understanding and awareness of the reliability of greywater recycling systems. Robust technologies for measurement, testing and monitoring of turbidity are available to enable accessible and smart visual displays of the readings, to show the instantaneous quality of the treated and recycled greywater flows. This is one of the important pathways for working towards the wider adoption of distributed greywater systems, when accompanied by periodic, routine testing for BOD and if possible, for microbiology. At locations where it may be very difficult to arrange for BOD and microbiological tests to be undertaken, residual chlorination (or bromination in a non-domestic system) should always be in place.

In meeting the first objective, consistency in theoretical measurement precision was demonstrated in practice, ensuring that the turbidity measurements shown in 
Figures 2 and 3 during greywater treatment were always taken as the mean of at least three readings. Calibration was practised using standard nephelometric suspensions. The quantitative reliability of the turbidity measurements delivered functional objectivity for process performance monitoring, management and control. The turbidity measurement approach performed well in representing both the observable practical and theoretical dynamics of the greywater treatment process throughout the 12-month experimental period. The variations in reaction turbidity in tank 1 showed consistency, and the treated greywater in tank 2 exhibited very stable turbidity readings following the physical and biochemical MBR treatment.

The second objective was met in the consistency of the turbidity parameter for regular in-building monitoring and management, and for its contribution to determining the degree of compliance of the treated water to BS 8525-2:2011. Turbidity is an aggregate measurement, representative of different substances present in a sample. Although being measurable as a quantitative parameter, its precise reaction chemistry at any moment is not necessarily correlated with the proportionate presence of a particular chemical species. This therefore, enables turbidity to be applied as a broad spectrum determinant for all current and future greywater quality standards. Common standards are required and they produce directly comparable data if the data are collected according to compatible formats and test conditions. In 2015, continuing work with British Standard Institution committees (BSi, CB505, 2015), showed that standard tests are essential for underpinning the technical expectations of the industry. Without pursuing the role of standards in a growing industry, manufacturers may operate using unsubstantiated assumptions about the efficiency of their treatment systems. The analytical results show the reliance that can be placed by complying with the maximum 
turbidity concentration of $<10$ NTU in BS 8525-2:2011, thus meeting the second objective.

The third objective was met through demonstrating that the application of the turbidity measurement principle meets many of the operational requirements of building managers and the facilities management (FM) teams for the greywater treatment system. A raised awareness by building services teams using turbidity monitoring, visual quality monitors and alarms, and integrated Building Information Management (BIM) systems leads to improved knowledge about and acceptance of the in-building control of greywater systems. These personnel need to be able to interpret the general readings upon which different types of practical decisions and actions are taken, for example for operating at the optimal performance of the plant. Repeatability in the measurement of turbidity makes this parameter suitable for non-technical users, for making visual measurements and observations about the degree of clarity or opaqueness of the treated greywater. The recognition of good visual quality provides an important indicator of users' familiarising skills, relating to the normal appearance of treated greywater and its appearance should the process malfunction or not run at optimal condition.

The FM teams do not usually need to know what are the detailed changes in theoretical reaction concentrations of the composite chemical species present in the treatment system at any one time; for example, the concentrations of ammonia and nitrite that are constantly oxidised in a well-aerated MBR system. Thus, the turbidity parameter is appropriate for its ease of operational interpretation by facilities and $\mathrm{M} \& \mathrm{E}$ engineers who are unfamiliar with the specific chemistry of the MBR process.

In the Proceedings of the 2003 Georgia Water Resources Conference, Ankcorn, a hydrologist of the US Geological Survey, discussed the potential benefits and 
limitations of applying turbidity for water quality monitoring. He reported problems arising from instrumental methods, and interference and bias arising from variation in suspended solids loadings. The interference and bias that Ankcorn discussed had reference to stochastic natural waters and probably has less relevance when applied to a well-controlled treatment process, specifically designed to remove suspended and total solids. This may be compared with the findings of Sadar (2003) (Hach Company), who reported that the presence of organic material in suspension/solution could adversely prevent some of the incident light reaching the detector. The Hach detection and measurement systems are now considerably superior (during the research period, 2012 to 2017), and there was no evidence of systematic interference in the turbidity measurements in the treated greywater and only a small number of outliers. The turbidity measurements in the untreated greywater can be seen in Figure 3.

Greywater treatment plants must be capable of processing all received greywaters irrespective of their compositional and temporal variation, the latter always relating to prior use. Water from handwashing can exhibit the characteristics of lightly loaded greywater, though compositional variability depends predominantly upon the users of hand basins, whether in the office, garden, home or on site. Thus, greywater treatment plant must have sufficient competency to operate well irrespective of the influent quality, and the measurement of greywater can be used to confirm the sufficiency and efficiency of treatment. Automatic turbidity monitoring and telemetry provides a principal system control for remote observation, capable of being remotely alarmed and shut down should conditions demand it.

The assessment of turbidity chemistry for indicating greywater quality met the four defined objectives when monitoring greywater treatment through an MBR and nanofiltration system. The theoretical and experimental findings were 
summarised as; (1) the measurement of turbidity on a daily basis improved the understanding of the Membrane Bio-Reactor (MBR) treatment process; the turbidity broadly co-varied with BOD results whereas, Electrical Conductivity (EC) variation provided little assistive data upon which to make operational decisions; (2) the turbidity measurements were a resilient indicator of process performance in the short-, medium- and long-term, as evidenced by the precision of turbidity readings and the variance in the treated turbidity readings of 0.05 NTU. So at a 95\% confidence level, the null hypothesis is strongly rejected; (3) the results confirmed the scientific basis for setting a maximum turbidity concentration of $<10 \mathrm{NTU}$ in the treated greywater in BS8525; (4) the fourth objective was met through demonstrating turbidity as an appropriate parameter for ease of measurement interpretation for applications in building monitoring and management, and for building systems control. Automatic monitoring and telemetry of the turbidity readings to the building management system will provide an important greywater control parameter that will be observed and alarmed remotely.

\section{5: Conclusions}

The rationale for including the empirical measurement of turbidity to demonstrate satisfactory management of greywater quality, greywater system operation, monitoring (manual and remote) and compliance in buildings was confirmed by the analytical results. These also demonstrated the appropriateness of the application of turbidity measurement for displaying the readings for manual and remote monitoring of process performance in commercial systems. Operational and other professional staff and members of the public are able to base judgements about the suitability and treatment performance of the greywater supply system by observing reliable, 
contemporaneous measurements of turbidity. Furthermore, in compliance with BS 8525-2:2011 and other international regulations, greater assurance in the use of greywater supplies in buildings can be achieved. The inclusion of turbidity monitoring and control is recommended, both internationally and in the UK, for all future greywater standards.

By establishing this principle of displaying the compliance of turbidity readings in buildings, the recommendation for its inclusion should become a more visible feature of International ISO and UK Standards, and of Building Regulations and building facilities design. Subsequently, online industry and public information will be enabled to become more widely provided and sought, whilst the interpretation of turbidity measurements will become a practice disseminated through industrial water engineering training.

Gulyas et al. (2009) suggested that greywater represents the most significantly reliable resource for achieving additional water resilience in domestic homes. Whilst greywater systems bring profound and climate-adaptive change, measurements of quality and composition are required to be appropriate, timely and accurate, to enable ease of interpretation by the intended users.

Take-up and diffusion of the technology conserves value in local water resources and contributes towards reducing the risks of water scarcity and vulnerability that are now well-documented for the UK water supply projections for 2030 and 2040 (Environmental Audit Committee, 2020). These observations and reflections about turbidity testing explicate its role in design recognition and consistency of operation, and can be integrated with remote sampling, telemetry and instrumentation into many types of buildings, for many different types of communities. This relatively inexpensive measurement technology makes its 
application favourable in any climate, in functional or luxury buildings, and in any

type of community for optimising water resources and recycling.

\section{Acknowledgements:}

Smith M.J., 2017. PhD thesis funded by EU Climate-KIC funding programme: grant number ARED0004_2013-1.1-009_P091_02.

Mr L. Johnen at Aquality Trading \& Consulting Ltd.

British Standards Institution.

\section{References}

Ankcorn, P.D. (2003). Clarifying Turbidity- the Potential and Limitations of Turbidity as a Surrogate for Water Quality Monitoring; U.S. Geological Survey, Atlanta, Georgia 30360-2824. In Proceedings of the 2003 Georgia Water Resources Conference, held 23-24 April 2003, University of Georgia. Editor: Hatcher, K.J., Institute of Ecology at the University of Georgia. 3039 Amwiler Road, Suite 130, Peachtree Business Center.

Aquality, (2015). Aqua-Recycling-Control Greywater Recycling System. Accessed 20 Mar 2018:http://www.aqua-lity.co.uk/wp-content/uploads/2015/02/Aquality-GreywaterRecycling-2014.pdf

Alharbi, S.K., et al (2019). Treatment of Ablution Greywater for Recycling by Alum Coagulation and Activated Carbon Adsorption. Arabian Journal for Science and Engineering. https://doi.org/10.1007/s13369-019-03834-6

Behzadian, K., et al (2014). Resilience-based Performance Assessment of Waterrecycling Schemes in Urban Water Systems. Procedia Engineering.Vol89.pp719-726.

BSi Committee Minutes, (2010). Committee CB/506 TC. Restricted.

BSi ISO (2020). Not published: draft concerning risk evaluation for water reuse. ISO/TC 282.

BS ISO 20761, (2018). Water reuse in urban areas - Guidelines for water reuse safety evaluation - Assessment parameters and methods. Standard preparation notification. May 2018. ISBN 9780580905902.

BSi Standard (2010). Greywater Systems, Part 1. Code of Practice. BS 8525-1:2010. BSi. London. ISBN 9780580634758

BSi Standard (2011) Greywater Systems, Part 2. Domestic Greywater Treatment Equipment: Requirements and Test Methods. BS 8525-2:2011. BSi. London. ISBN 9780580634765

BSi Standard (2009 plus 2013 addition). Rainwater harvesting systems. Code of practice. BS 8515:2009+A1:2013. BSi. London. ISBN 9780580783531

Casey, B et al (2020) Resilience by design: A deep uncertainty approach for water 
systems in a changing world. Water Security. 9 (2020) 100051

Chaillou, K. et al., 2010 Bathroom greywater characterization and potential treatments for reuse. Water, Air and Soil Pollution. 215(1-4), pp.31-42.

Climate Change Committee (2017) UK Climate Change Risk Assessment. Presented to Parliament pursuant to Section 56 of the Climate Change Act 2008. www.gov.uk/government/publications. Web ISBN 9781474137423

Council Directive 2000/60/EC. (2000) Establishing a framework for community action in the field of water policy. (Water Framework Directive).

Council Directive 2006/7/EC of the European Parliament and of the Council of 15 February 2006, concerning the management of bathing water quality and repealing Directive 76/160/EEC.

Davies-Colley, R.J., and Smith, D.G. (2007) Turbidity, Suspended Sediment and Water Clarity: A Review. Journal of American Water Resources Association. Vol 37-

(5).pp.1085-1101. https://doi.org/10.1111/j.1752-1688.2001.tb03624.x

Defra, (1999) The Water Supply (Water Fittings) Regulations 1999. HMSO.

Defra, (2016) Creating a great place for living. Enabling resilience in the water sector, March 2016. PB14418. Crown Copyright. London.

https://www.gov.uk/government/publications/water-sector-improving-long-termresilience. Accessed on $1^{\text {st }}$ October 2020.

www.gov.uk/government/uploads/system/uploads/attachment_data/file/504681/resilien ce-water-sector.pdf

Diaper, C., Jefferson, B., Parsons, S.A. and Judd, S.J. (2001) Water Recycling Technologies in the UK. Water and Environment. 15(4), 282-286.

Diaper, C. Toifl, M. and Storey, M. (2008) Greywater Technology Testing Protocol. CSIRO: Water for a Healthy Country National Research Flagship.

Dixon, A., Butler, D., Fewkes, A. and Robinson, M. (1999) Measurement and Modelling of Quality Changes in Untreated Greywater. Urban Water. 1(4), 293-306.

Dixon A., Butler D. and Fewkes A. (1999) Guidelines for Greywater Re-Use: Health Issues. Water and Environment. 13(5), 322-326.

Environmental Audit Committee (2020) National Audit Office report on water supply and demand management (March 2020), from Philip Dunne. Environmental Audit Committee, eacom@parliament.uk. House of Commons. London

Ernst M, Sperlich A, Zheng X, Gan Y, Hu J, Zhao X, Wang J.J.M., 2006 An integrated wastewater treatment and reuse concept for the Olympic Park 2008, Bejing.

Desalination. 202(1-3),pp.293-301.

European Water Framework Directive, (2000) European Council Directive, 
Fernandes T.M.A., Schout S., De Roda Husman, A.M., Eilande, A., Vennema, H., van Duynhoven, Y.T.H.P., (2007) Gastroenteritis associated with accidental contamination of drinking water with partially treated water. Epidemiology and Infection. 135(5), 818826.

Fewtrell, L. and Bartram, J., (2001) Water Quality: Guidelines, Standards and Health. Assessment of risk and risk management for water related infectious disease. World Health Organization Water Series.

Fielding, K.S., Dolnicar, S., Schultz, T. (2018) Public acceptance of recycled water. International Journal of Water Resources Development. 35(4):551-586. https://doi.org/10.1080/07900627.2017.1419125

Fountoulakis, M.S., Markakis, N., Petousi, I. and Manios, T., (2016) Single house onsite grey water treatment using a submerged membrane bioreactor for toilet flushing. Science of The Total Environment, 551-552:706-711. DOI: 10.1016/j.scitotenv.2016.02.057

Friedler, E., (2004) Quality of Individual Domestic Greywater Streams and its Implication for On Site Treatment and Re-Use Possibilities. Environmental Technology. 25(9), 997-1008.

Ghaitidak, D. and Yadav, K., (2013) Characteristics and Treatment of Greywater- A Review. Environmental Science and Pollution Research. Vol 20(5), 2795-2809. http://link.springer.com/article/10.1007/s11356-013-1533-0

Gulyas, H., Choromanski, P., Muelling, N. and Furmanska, M,. (2009). Towards chemical-free reclamation of biologically pretreated greywater: solar photocatalytic oxidation with powdered activated carbon. Journal of Cleaner Production. 17, 1223 1227.

Holden, W.S., (1970). Water Treatment and Examination. J. \& A. Churchill. London.

Hourlier, F., Masse A., Jaouen P., Lakel A., Gerente C., Faur C and Le Cloirec P. (2010). Membrane process treatment for greywater recycling: investigations on direct tubular nanofiltration. Water Science and Technology, 62(7), 1544-1550.

Hyde, K. and Smith, M.J. Greywater Recycling and Reuse (2019). In 'Urban PollutionScience and Management', pp 211-220, (eds. Charlesworth, S. and Booth, C.). Refereed book. John Wiley \& Sons Ltd, 2019. LCCN 2018028469 (ebook). ISBN 9781119260462 (pdf). ISBN 9781119260509 (epub). https://lccn. loc. gov/2018014793.

Ilemobade. A.A., Olanrewaju. O.O., Griffioen. M.L., (2013). Greywater reuse for toilet flushing at a university academic and residential building. Water SA. 39(3), 351-360.

Kant, S. and Jaber, F.H., (2020). Advanced filtration in greywater treatment: a modelling approach with water reuse perspectives. Urban Water Journal. Published online 08 October 2020. doi.org/10.1080/1573062X.2020.1828498 
Konrad, K., and Bohle, K. (In press) Socio-technical futures and the governance of innovation processes- An introduction to the special issue. Futures. In press 2019. https://doi.org/10.1016/j.futures.2019.03.003

Lazarova, V., Hills, S., and Birks, R. (2003). Using recycled water for non-potable, urban uses: a review with particular reference to toilet flushing. Water Supply (2003) 3 (4): 69-77. doi.org/10.2166/ws.2003.0047

Memon, F.A. and Ward, S., (2014) Alternative Water Supply Systems. IWA Publishing. 9781780405506 or 9781780405513 . London.

Millard, P., (16 August 2017). Unreported incidents involving greywater system configuration. Personal communication

National Infrastructure Commission, (2017) UK Climate Change Risk Assessment 2017 Evidence Report. Crown copyright. London. Web ISBN 9781474137423

Nolde, E. (1999) Greywater reuse systems for toilet flushing in multi-storey buildingsover ten years' experience in Berlin. UrbanWater. 1, 275-84. Based upon Nolde, E., Dott,W., (1992). Verhalten von hygienisch relevanten Bakterien und Pilzen im Grauwasser-Einuss der UV-Desinfektion und Wiederverkeimung. gwf Wasser Abwasser $132,108 \mathrm{e} 114$.

Po, M. Kaercher, J. D. and Nancarrow B. E. (2003). Literature review of factors influencing public perceptions of water reuse. CSIRO Land and Water, Technical report 54/03. Accessed 31/10/2014.

Sadar, M.J. (2003). Proceedings of the Federal Interagency Workshop on Turbidity and other Sediment Surrogates: Appendix 2, Papers submitted as part of the "Turbidity and Other Sediment Surrogates Workshop," $30^{\text {th }}$ April- $2^{\text {nd }}$ May 2002, Reno, Nevada. Eds. Gray, J.R. and Glysson, G.D. In US Geological Survey Circular 1250. Library of Congress. Reston, Virginia, 2003.

Sage, A.P., Rouse, W.B. (Eds.) (2009). Handbook of Systems Engineering and Management. Wiley.

Saidi, A., Masmoudi, K., Nolde, N., Elamrani, B.E. and Amraoui, F. (2017). Organic matter degradation in a greywater recycling system using a multistage moving bed biofilm reactor (MBBR). Water Science \& Technology (2017) 76 (12): 3328-3339.

Sapkota, M. et al (2015) An Overview of Hybrid Water Supply Systems in the Context of Urban Water Management: Challenges and Opportunities. Water 2015. 7(1).pp153174. https://doi.org/10.3390/w7010153

Schoen, M.E., Jahne, M.A. and Garland, J. (2018) Human health impact of non-potable reuse of distributed wastewater and greywater treated by membrane bioreactors. Microbial Risk Analysis. Vol.9. pp72-81. https://doi.org/10.1016/j.mran.2018.01.003 
Singh, V., Kaur, A, Ghawana, T. and Gupta, N.C. (2018) Feasibility Study of Treatment Technologies for Greaywater to Enhance Water Security. International Journal of Applied Engineering Research. Vol.13(6), 4042-4048. Research India Publications. ISSN 0973-4562. http://www.ripublication.com

Slovic, P. (1989) Perception of risk. Science. 236(4799), 280-285 (DOI: $10.1126 /$ science.3563507).

Smith, M.J., 2017). PhD thesis. University of XXXX.

Taylor J. K., Stanley T.W. (1985). Quality Assurance for Environmental Measurements, STP867. Committee/Subcommittee: D22.01. Center for Analytical Chemistry, National Bureau of Standards, Gaithersburg, MD, ASTM. Source: DOI: 10.1520/STP30283S.

The, X.Y., Poh, P.E., Gouwanda, D., Chong, M.N., (2015) Decentralized light greywater treatment using aerobic digestion and hydrogen peroxide disinfection for non-potable reuse. Journal Cleaner Production. 99:305-311

UK Government, (1936) The Public Health Act 1936 (26 Geo 5 \& 1 Edw 8 c49). Hansard.

UK Government, (1937) The Public Health (Drainage of Trade Premises) Act 1937. Hansard.

UK Government, (2003) The Water Act UK, 2003, c 37. Hansard.

UK Government, (2016) The Water Supply (Water Quality) Regulations 2016.

United Nations, (2016). 17 Sustainable Development Goals (SDGs) of the 2030 Agenda for Sustainable Development; SDG 6, 'Clean Water and Sanitation'

USEPA, (2012) Guidelines for Water Reuse. Ohio.

Waxman, H. (1996). Testimony reported to the congressional Record, Extension of Remarks for the $104^{\text {th }}$ Congress $2^{\text {nd }}$ Session, introducing HR3280, 19 April 1996.

Water Act UK, (2003). HM Government, 2003, c37.

Watts, D. J., Dodds, P. S. (2007) Influentials, Networks and Public Opinion Formation. Journal of Consumer Research. 34(4),1-25. doi: 10.1086/518527.

WHO, World Health Organisation, (2006) Guidelines for the safe use of wastewater, excreta and greywater- Volume 4. ISBN: 924154685 9. Geneva.

WRAS, Water Regulations Advisory Service, 1999.

Wu, B., (2019). Membrane-based technology in greywater reclamation: A review. Science of the Total Environment. 656,184-200. 


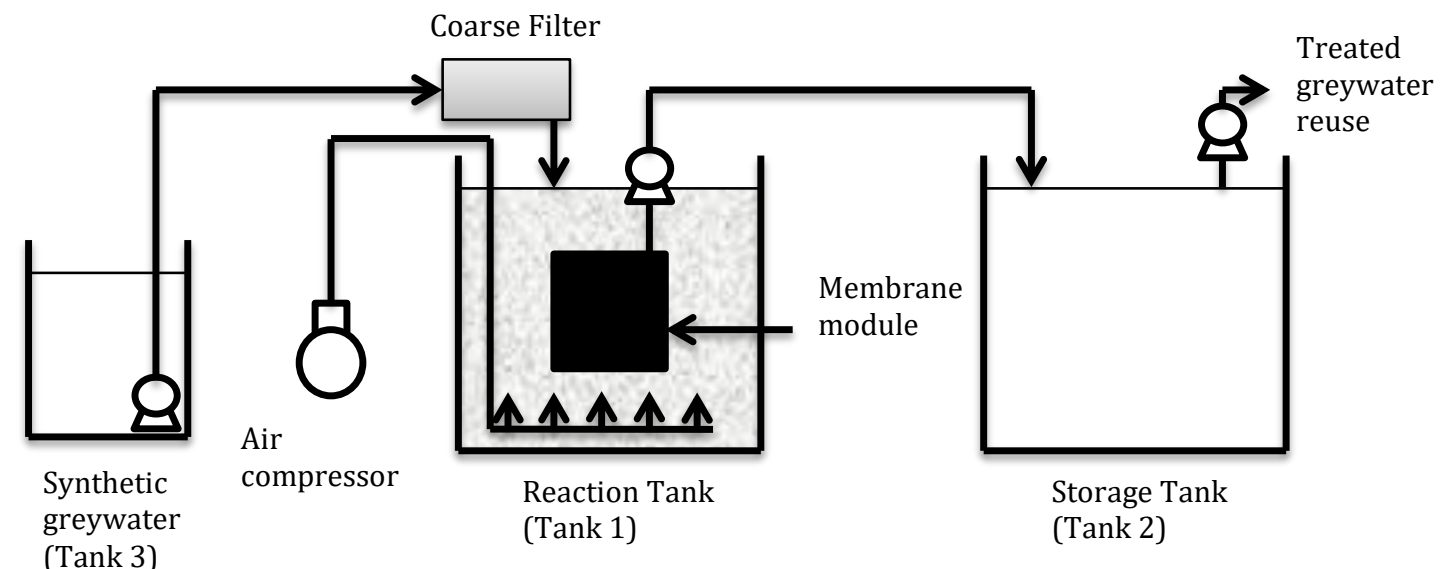

